\title{
A Critique of the Methodological Approaches to Hotel Guest Green Consumerism Empirical Researches Since 2000
}

\author{
Mr. Cleopas Njerekai* \\ Department of Tourism and Hospitality Management, Midlands State University, Zimbabwe
}

*Corresponding Author: Mr. Cleopas Njerekai, Department of Tourism and Hospitality Management, Midlands State University, Zimbabwe

\begin{abstract}
This article reviews and critiques the methodological approaches and processes adopted to date by past researchers on hotel guest green consumerism with a view to making methodological improvements in this academic discourse. 100 journal articles published since 2000 were reviewed to produce this article. The short time span covered by the study reveals the recency of hotel guest green consumerism studies as an academic discourse, with most of the publications appearing after 2005. This research revealed that previous researches on hotel guest green consumerism contained conclusions based on studies mostly carried out, out of context, with unknown sampling frames and therefore most probably unrepresentative samples. Most of these studies have also been carried out in the global north such as the USA and therefore raising questions on the applicability of the recommendations emanating from them to the global south. This study recommends that the methodological shortcomings raised in this paper be addressed in order to increase the validity and reliability of future research findings in this discipline. There is also a dire need to spread research on hotel guest green consumerism issues to developing countries as hotels in these countries have different patronage and operate under different PESTEL environments.
\end{abstract}

Keywords: Hotel, Green Consumerism, Green Guest, Methodological Weaknesses, Methodological Approaches

\section{INTRODUCTION}

Concern about environmental sustainability and climate change in the hotel industry has significantly gained prominence in the last two decades (Baker et al 2013, Horner and Swarbrooke 2006; Han et al 2011; Miller 2003). The global hotel industry, has since engaged a number of tools, change agents and approaches in a bid to green their operations. These have included eco-rating schemes, environmentally friendly management policies and practices, the media, environmental pressure groups and green incentives. However, more recently, the hotel industry has witnessed an increasing number of tourists seeking hospitality establishments that are environmentally friendly (Weisenburg, Redington and Kutyla, 2008). This development clearly emphasises the fact that, in the drive towards the greening of hotel operations, it is not only the hotel establishments (supply side) which should green their operations but also the guests themselves (demand side) who should turn into or be turned into 'greenies'. This realisation and the need to accentuate this demand side of going green has triggered a significant number of researches on hotel green guest consumerism but with most of the publications appearing after 2005.

While going through some of the published journal articles on this matter, the methodological sections of these articles revealed several methodological weaknesses acknowledged by the authors themselves which had a huge potential to compromise the validity and reliability of their findings. This prompted this researcher to review the methodological approaches and processes of even more journal articles published since 2000 with a view to suggesting improvements that could increase the worthiness of research findings on this matter in future research studies.

\section{Methodology}

To produce this paper, 100 journal articles published since 2000 and related to the topic were read through and used to produce a methodology map structured along the sub-titles in this paper. More journal articles could not be read due to data saturation and redundancy. Descriptive statistics were then used to present and analyse the data. 


\section{FINDINGS}

\subsection{Research Designs Adopted to Date on Hotel Green Guest Consumerism Studies}

According to Altinay and Paraskevas (2008) the research design, is the operational framework within which any research is carried out. Its function is to ensure that the evidence obtained enables the researcher to address the research problem and the resultant research objectives and questions as unambiguously as possible. In relation to the related journal articles reviewed by the researcher, 99\% of them adopted a mixed methods approach but with the quantitative aspect being more pronounced in the data analysis section and not in the selection of study areas, participants and sampling methods.

\subsection{Research Philosophies in Hotel Guest Green Consumerism Studies}

Constructivism was the dominant research philosophy for the journal articles under review but with some elements of pragmatism. As observed by Yin (2003), constructivism claims that truth is relative and that it depends on one's perspective. This philosophy therefore recognizes the importance of the subjective human creation of meaning, but does not wholly reject some notion of objectivity (Yin 2003). Constructivism has also been dominant for these studies as they are based on perspectives and attitudes of hotel guests which in themselves are highly subjective.

\subsection{The Study Area and Units}

As shown in figure 1.1, 44\% of the 100 researches on hotel guest green consumerism that the researcher came across were conducted in the United States of America. Other significant areas identified were Australia and Taiwan. This skew in existing literature could be a reflection of the level of consciousness of green consumerism in these countries or general lack of researchers and interest in the subject in other parts of the world especially in Africa where issues related to green tourism and global warming are still largely viewed as a western phenomenon.

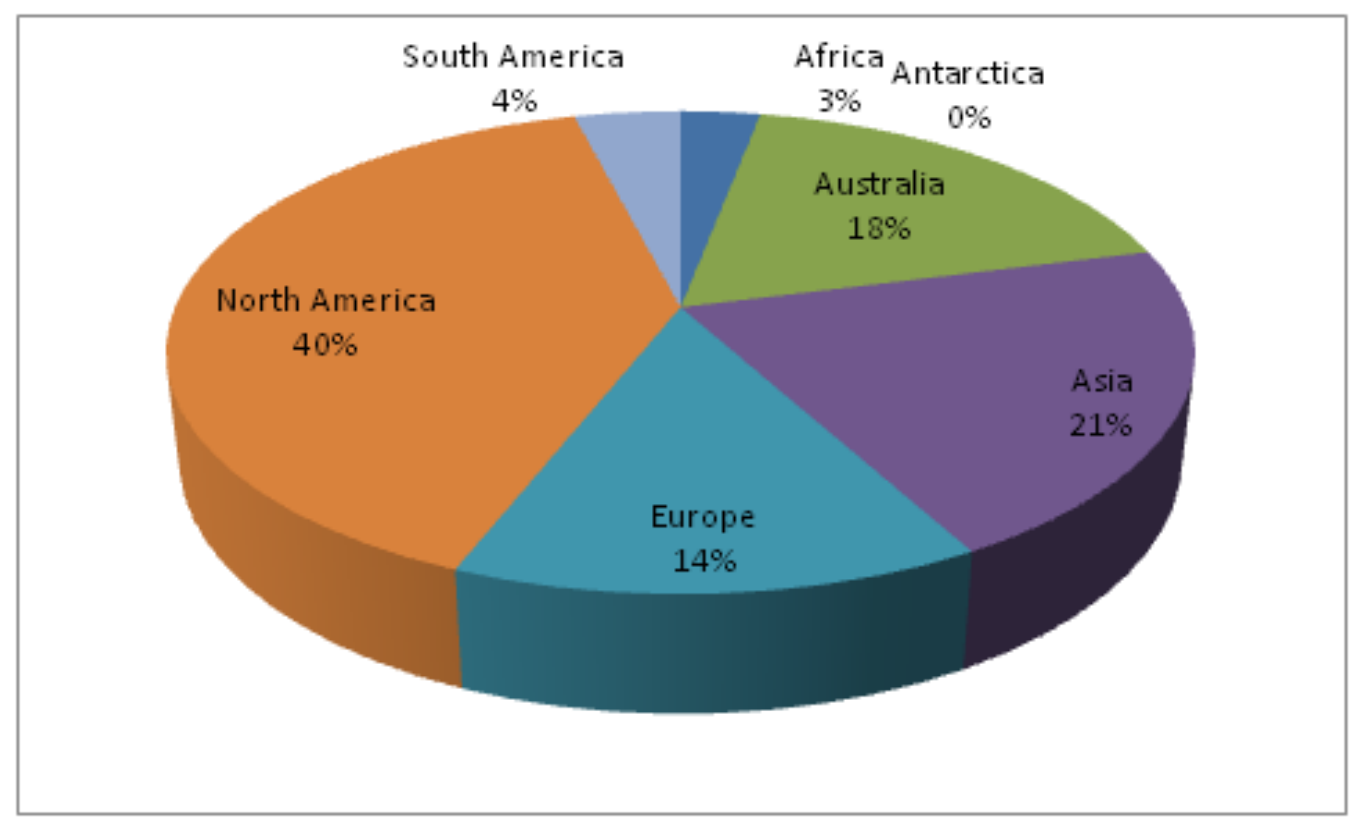

Figure1.Continental distribution of green guest consumerism studies from 100 related journal articles

In relation to study units and settings, this research revealed that an insignificant number of researches have been carried out in actual hotel settings. In fact, settings other than hotels, such as airports, train and bus stations, visitor information centres, supermarkets and many more have been the dominant settings in this academic discourse as shown in figure 1.2. As partially experienced by this writer, hotel managers could be denying researchers' access to their properties and guests for fear that this could negatively impact guest experiences. Therefore, to circumvent this problem, most researches carried out on hotel green consumerism issues to date have been carried out on virtual spaces and online. For the few that have been carried out in actual hotel settings, these have turned out to be hypothetical hotel rooms (Millar and Baloglu 2011) or hotels used as teaching laboratories such as the Statler Hotel at the Cornell University Campus in the U.S.A. (Susskind 2014). 
A Critique of the Methodological Approaches to Hotel Guest Green Consumerism Empirical Researches Since 2000

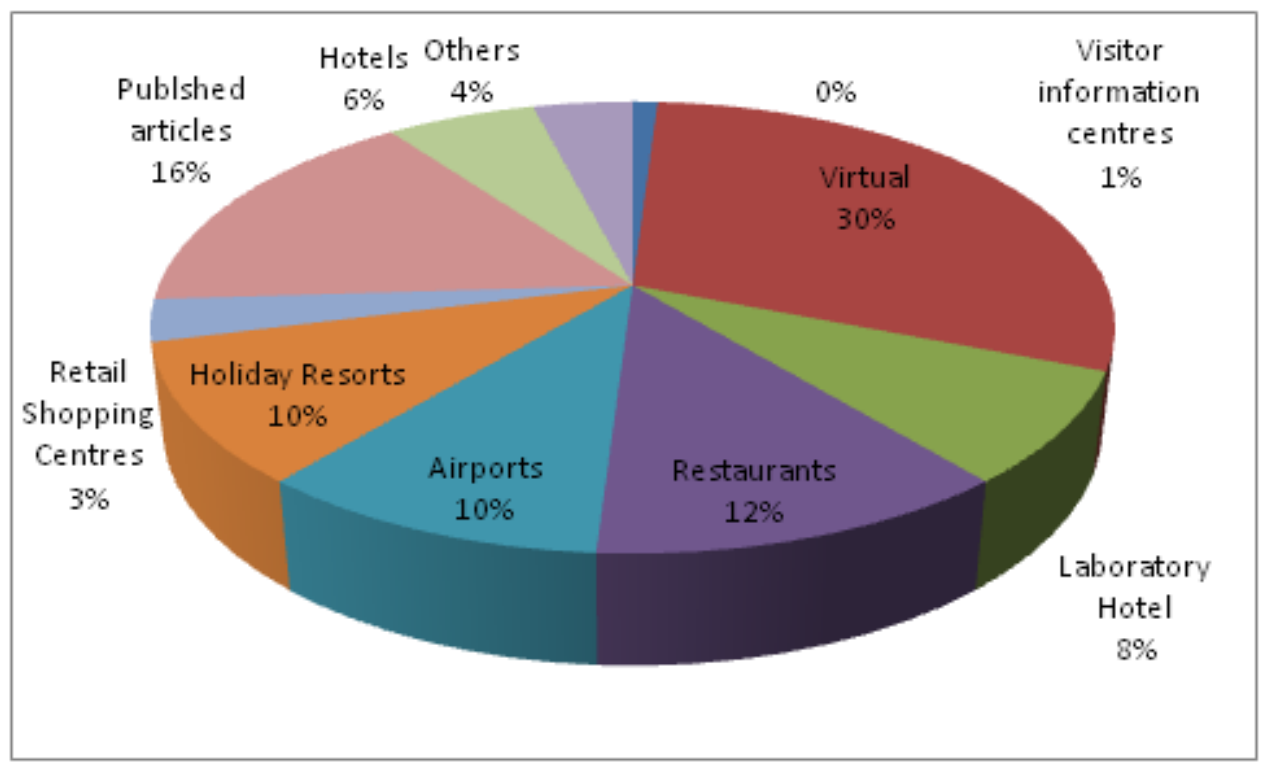

Figure2. Previous hotel guest green consumerism study settings for 100 related journal articles

\subsection{Study Participants and Sample Size Determination}

\subsubsection{Study Participants and Sampling Frames}

As shown in figure $1.3,80 \%$ of the 100 journal articles reviewed for this study had unknown sampling frames and therefore one wonders how the study samples were arrived at. In the few instances where sampling frames were indicated, these were provided for by online research company data bases from which researchers accessed hotel guest contact details most likely for a fee. This research revealed that such centralized data bases were non-existent in Zimbabwe, albeit in many other developing countries worldwide. Therefore, interested private companies in these countries could data mine and provide such services to potential researchers to facilitate research. However, the negative impacts on potential and actual guests of access to information in such data bases, including possible unsolicited e-mails and telephone interviews still needs further probing.

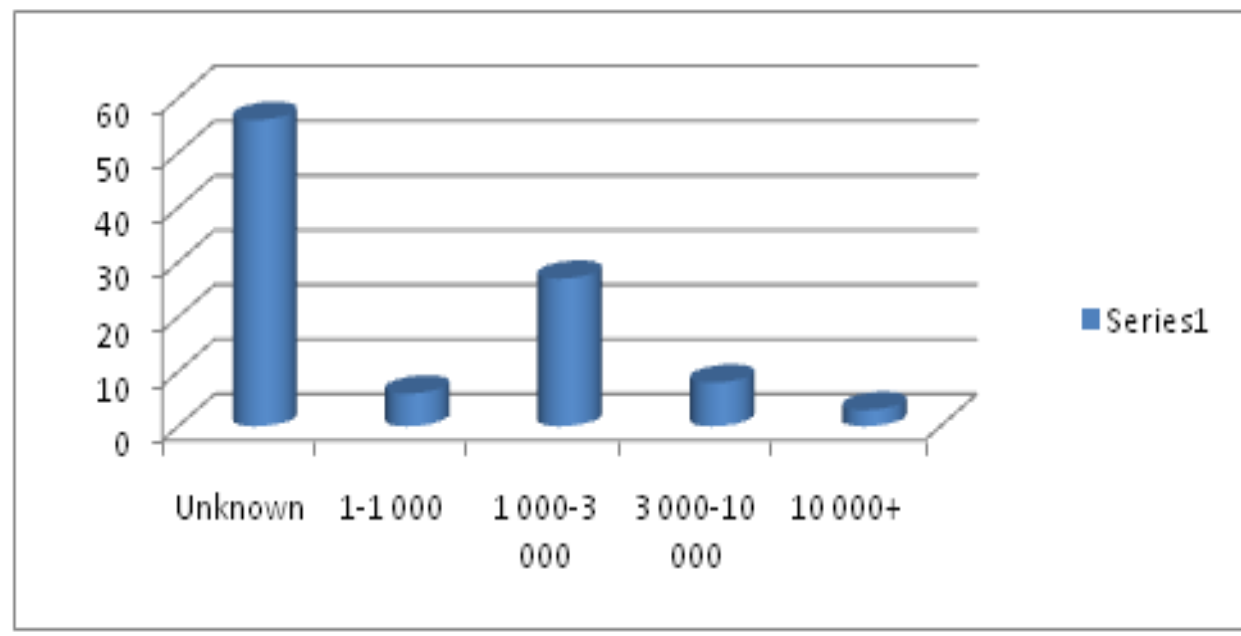

Figure3. Sampling frames for 100 previous studies on hotel green guest consumerism

\subsubsection{Sample Size Determination}

As shown in figure 1.4, for the related journal articles reviewed for this study, sample sizes ranged between 166 and 1000 respondents with most clustering occurring between 300 and 500. With such samples and for countries as huge as the USA, it is clear that these samples have largely been unrepresentative and hence the generalizability of the study findings has so far been compromised. The researchers in these studies openly admit this weakness in their methodologies. Calls have therefore been made by some researchers such as Baker et. al. (2013) to study larger samples to yield more generalisable findings. 


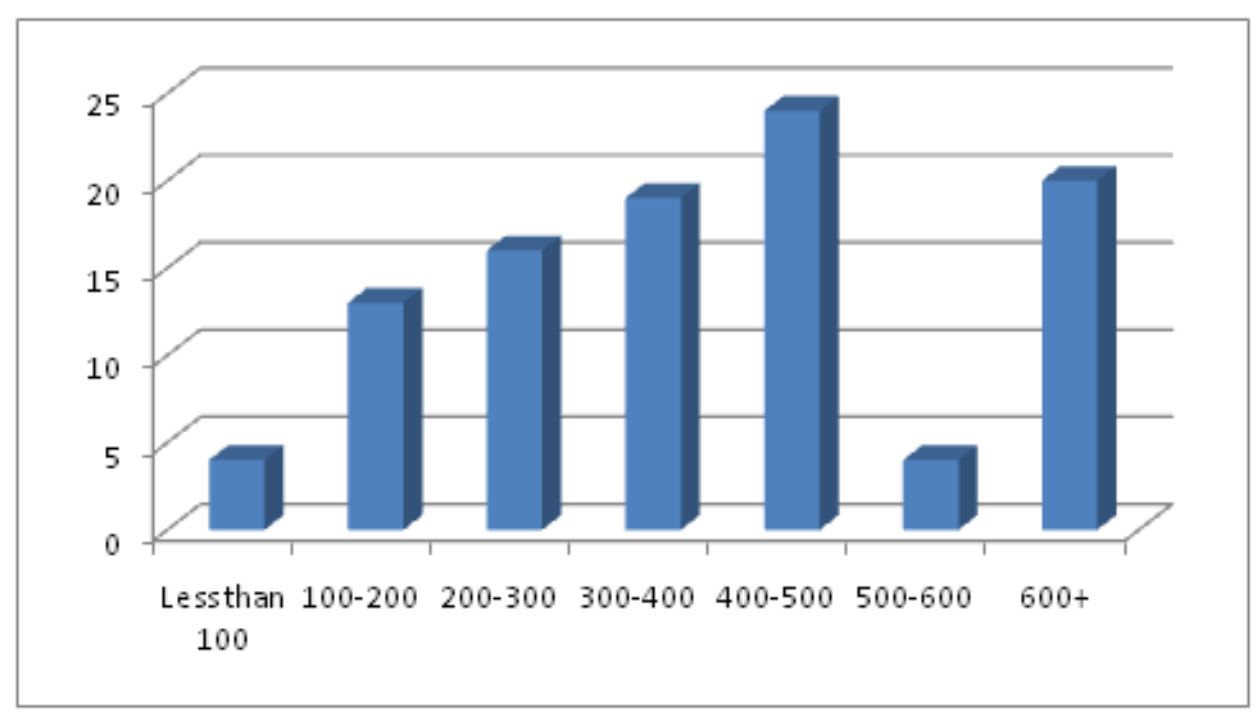

Figure4. Actual sample sizes for 100 previous studies on hotel green guest consumerism

\subsection{Selection of Actual Respondents}

The non-probability sampling technique of the convenience type has been the dominant sampling method in the papers under review. In this method, only guests who were willing and able to participate in the researches did so. Although this method has its limitations especially in terms of the representativeness of hotel guest populations, it is a commonly used technique in studies where the exact sample frames cannot be established and samples cannot be rigorously analyzed to determine possible bias and likely error (Brotherton 2008).There are several studies from the methodology map and other published articles that have used this approach with some laudable results. For most of these studies, the researchers tried by all means to get representativeness of the population especially in terms of socio-demographic aspects of the respondents by deliberately ensuring diversity in respondents' demographic characteristics, especially in terms of their origin, gender and age at data analysis.

\subsection{Data Collection Methods and Instruments}

From the methodology map, self-administered questionnaires and likert scales have been the main methods of collecting data for hotel guest green consumerism studies to date. Of the 100 related journal articles reviewed for this article, Netnography, mainly through blast e-mails has been the dominant data collection method. The main challenges which have been faced with this method has included low response rates and over-reliance on respondent memories hence to some extent compromising the validity and reliability of the research findings.

\subsection{Strengths and Limitations of Previous Researches in Terms Data Collection Processes and Research Worthiness}

Researches on hotel guest green consumerism to date have mostly been qualitative and yet for some time now, the trustworthiness of qualitative researches has often been questioned, especially by quantitative researchers perhaps because their concepts of validity and reliability are not adequately addressed in these researches. Even today, some academic journals are still finding it difficult to publish articles founded on qualitative enquiries. Therefore, in response to this scepticism, some renowned naturalistic investigators such as Lincoln and Guba (2006); Miles and Hubermann (1994) among other researchers, have come up with different terminologies to replace the concepts of validity and reliability associated with quantitative research but which also ensure the trustworthiness of naturalistic inquiries. These authors believe that four criteria should be considered by qualitative researchers in pursuit of trustworthy studies. These terms are; credibility for internal validity, transferability for external validity, dependability for reliability and conformability for objectivity. For the researches under review, numerous attempts were identified which were intended to ensure the worthiness of the data collected. The specific actions that were taken and revealed in these papers are presented in this section. 


\subsubsection{Aspects of Credibility}

One of the key criteria addressed by positivist researchers is that of internal validity, in which they seek to ensure that their studies measure or test what is actually intended. In naturalistic research, the equivalent concept, that is, credibility, deals with the question, "How confident can we be with the conclusions drawn from the research data or how congruent are the findings with reality?" The following provisions were evident and put in place to ensure the credibility of the data collected for the journal articles under review.

\section{a) Measures to Ensure Frankness and Freeness in the Acquisition of Data from the Guest}

The convenience sampling method characterizing the researches under review were adopted to ensure that only those participants genuinely willing to provide the information did so. There was thus implied informed consent as the hotel guests involved had the freedom to complete or not to complete the questionnaires or participate in the study. However, the researchers do not specify whether the participants signed research consent forms or not.

\section{b) Comparison of Current Data Collection Methods and Processes with Previous Comparable Studies}

This was evident in the papers and was done to assess the degree to which the data collection methods were congruent with those of previous studies. Silverman (2006) considers that the ability of a researcher to relate his or her methodology to existing studies is a key criterion for evaluating works of qualitative inquiry. In this case, the data collection methods and processes in these journal articles were compared with numerous visitor surveys done elsewhere at various scales.

\section{c) Triangulation}

This was one of the key methods of ensuring validity and reliability in the papers under review. The collection of data from different hotels and from guests with multicultural backgrounds ensured this.

\section{d) Representativeness of Study Units and Participants}

Participant representativeness in terms of their socio-demographic aspects was also achieved in the papers by stratifying the responses by gender and age and other socio-demographics.

\section{e) Data Editing and Validation by the Researcher}

Lincoln and Guba (1985) also consider this to be one of the most important provisions that can be made to bolster a study's credibility. Other authors such as Ruane (2004), Neuman (2007) also concur that, data analysis and verification is something one brings forth with them from the field, not something which can be attended to later. In the papers under it was not in black and white that this was done but it can be implied as the authors of these papers are seasoned writers and academics.

\subsubsection{Aspects of Transferability}

Just as in external validity, transferability is concerned with the extent to which the findings of one study can be applied to other situations. In positivist work, this concern often lies in demonstrating that the results of the work at hand can be applied to a wider population. This was observed to be the greatest shortcomings of the studies under review as already alluded to in item 3.4 of this article.

\subsubsection{Aspects of Dependability/Reliability}

In addressing the issue of reliability, the positivist employs techniques to show that, if the work were repeated, in the same context, with the same methods and with the same participants, similar results would be obtained. However, as Shenton (2004) note, the changing nature of the phenomena scrutinised by qualitative researchers renders such provisions problematic in their work. Lincoln and Guba (1985) highlight how the investigator's observations are tied to the situation of the study, arguing that the "published descriptions are static and frozen in the "ethnographic present". They go on to stress the close ties between credibility and dependability, arguing that, in practice, a demonstration of the former goes some distance in ensuring the latter.

\subsubsection{Conformability}

Patton (2002) associates objectivity in science with the use of instruments that are not dependent on human skill and perception. He recognises, however, the difficulty of ensuring real objectivity, since, 
as even tests and questionnaires are designed by humans, the intrusion of the researcher's biases is inevitable. The concept of conformability is the qualitative investigator's comparable concern to objectivity (Shenton 2004). In the studies under review, the measures taken to ensure credibility, transferability and dependability could also have ensured that the research findings are solely a result of the experiences and ideas of the informants, rather than the characteristics and preferences of the researcher. Therefore, in general, a number of steps have so far been taken to ensure the worthiness of the data collected for hotel green guest consumerism studies although a lot more could be done.

\subsection{Strengths and Limitations of the Studies in Terms of Measurement and data Collection}

The key challenge gleaned by the researcher from the published articles was the denial of access by hotels to collect the data. Out of the 100 published journal articles related to this topic under review, none of them included a section on the pilot study and adopted emergent design flexibility. This is an approach in which the data collection methods are adjusted to accommodate emerging challenges during data collection.

\subsection{Data Capturing and Analysis}

Data analysis techniques for the journal articles under review were dependent on the study objectives. Parametric tests were the main statistical data analysis techniques $(80 \%)$ for the journal articles under review. However, the specific technique for each study varied depending on the study topic. Specific examples included the use of conjoint analysis to determine how hotel guests choiced their hotels and the use of 't' values, ANOVA and MANOVA to establish relationships between and among variables respectively. Hierarchical regression, structural equation modeling, Cluster analysis and Cronbach's alpha were also other study specific statistical data analysis techniques that were used in the papers under review. Triangulation of data analysis techniques was also a common feature of the articles. The use of inferential rather than descriptive statistical methods of data analysis should be encouraged for they provide much more relevant and richer and interpretation of the research results.

\subsection{Ethical Considerations in the Studies Under Review}

Ethical issues with regards to hotel guest green consumerism studies are basically related to issues of informed consent, honesty, privacy, and avoidance of harm to participants and it is incumbent upon researchers to uphold these issues during research. In this regard, informed consent forms should be completed by research participants or in some instances consent statements should be built into the introductory sections of data collection instruments such as questionnaires so that completing the questionnaire implies that the respondents knowingly and willingly participate in the research.

The issue of providing incentives to research participants was picked up in 5 of the 100 reviewed journal articles. These incentives were given research participants where levels of non-response error were expected to be incredibly high. In this case, tokens of appreciation in both monetary and nonmonetary forms are offered to participants upon providing the required information. In the five articles where participants were incentivized, the monetary incentive varied from US\$3 to US $\$ 10$ worth of free food vouchers. This issue of incentivizing respondents is a controversial one with some researchers such as Wertheimer and Miller (2008)pinioning that this could induce a high response error with most of the responses being manufactured to please the researchers. However, the contingent and consequential theorists contest that these ethical issues should be breached whenever the result of such an act is beneficial to the research. In this case the five cases picked up could be justified by this understanding.

\section{CONCLUSiOnS AND RECOMMENDATIONS}

The mixed methods research design adopted to date on researches of this nature could continue to dominate researches in this area as aspects of both quantitative and qualitative nature are unavoidable in these studies. Therefore, efforts to continue quantifying the quantifiable from these qualitative findings should be upheld.

$>$ While constructivism as a research philosophy could continue to dominate researches in this area, one would wish that the pragmatic dimension be more equally pronounced so that these researches become more valuable to practitioners. 
$>$ In line with calls by various researchers such as Baker et al. (2013), Millar and Baloglu (2011) and many more, studies examining hotel consumer behaviour should be undertaken in actual hotel settings to increase their validity. There is therefore a need for researchers to dialogue with hotel owners to allow researches to be carried out within their premises and with clients but in a winwin situation. Other than this, all tourism and hospitality training institutions, especially at tertiary level, should own and/or run laboratory hotels where experiments with willing guests and other hotel environs can be undertaken.

$>$ This research noted the presence of online research company data bases in some countries such as the USA from which researchers could access hotel guest contact details most likely for a fee. Further investigations revealed that such centralized data bases were non-existent in many developing countries worldwide. Therefore, interested private companies in these countries could data mine and provide such services to potential researchers to facilitate research in this area. However, mitigation strategies for the negative impacts on potential and actual guests of access to information in such data bases, including possible unsolicited e-mails and telephone interviews would need to be put in place.

$>$ The non-probability sampling technique of the convenience type and the associated mixed methods of data collection and instruments such as likert scales and questionnaires might not change in the near future for this discipline as it is mainly to do with very subjective elements of perception, attitude and behaviour change. However, campaigns need to be embarked on to encourage guests to participate in these studies and therefore reduce the levels of non-response error.

$>$ As already alluded to in this paper, the credibility, transferability, dependability and conformability of researches carried out in this area needs to be ensured by adopting the various hints highlighted in this article.

$>$ In data analysis, and where data is being collected from several settings and respondents, data collection and analysis could occur concurrently to allow amble time for data editing and validation. The choice of data analysis techniques could continue to depend on the study objectives and the resultant statistical decision trees.

$>$ It is incumbent upon researchers to uphold issues of informed consent, honesty, privacy, and avoidance of harm to participants during research. Informed consent forms should be completed by research participants or in some instances consent statements should be built into the introductory sections of data collection instruments such as questionnaires so that completing the questionnaire implies that the respondents knowingly and willingly participated in the research.

On the other hand, where high levels of non-response error are expected, tokens of appreciation could be given to participants to encourage participation. However, researchers should advise the respondents not to build bias into their responses because of the token. Taken from another angle, such incentives could actually excite guests and enhance their hotel experiences instead of inconveniencing them. Souvenirs like themed t-shirts, pens etc could be more favourable to guests than monetary incentives.

$>$ This paper finally recommends that, as researchers embark on their quest for knowledge on this topic, they should take hid of calls from previous researchers to focus on the actual behaviours of hotel guests and on how best to turn them into greenies (Jin-Soo et. al.2010). Susskind $(2014,236)$ clearly pointed out that, "it would be more valuable to test guest reactions to sustainability initiatives using a larger sample of hotels across different segments, geographic locations and socio-demographic groups". Barber(2014) suggested that future studies be conducted in other countries given the differences in cultural values and resource availability among them. He added that such studies should take into account guests' actual hotel stay activities. Baker et. al. (2013) further stressed that future studies in this area needed to examine hotel customer behaviour in actual hotel settings to increase their validity. He reiterated that there was need to assess larger samples in different locations and cultures to achieve generalizability of results and enhance a more global understanding of the phenomena under study. 


\section{CONTRIBUTION OF THIS RESEARCH}

This research is the first of its kind in the field of hotel guest green consumerism. The research reveals some strengths and weaknesses in the researches carried out to date on hotel guest green consumerism. The idea is to encourage future researchers to avoid them and hence improve the validity and reliability of future findings on this matter. The research also reveals the dire need to spread research on hotel guest green consumerism issues to developing countries as hotels in these countries have different patronage and operate under different PESTEL environments.

\section{REFERENCES}

[1] Baker, M. A., Davis, E. A. \&Weaver, P. A. (2013). Eco-friendly Attitudes, Barriers to Participation and Differences in Behaviour at Green Hotels. Cornell University Quarterly, 55(1), 89-99.

[2] Horner, S. \&Swarbroke, J. (2006). Consumer Behaviour in Tourism. London: Butterworth-Heinemann.

[3] Han, H., Hsu, L. T., Lee, J. \&Sheu C. (2011). Are Lodging Customers Ready to go Green? An Examination of Attitudes, Demographics and Eco-friendly Intentions. International Journal of Hospitality Management, 30, 345-355.

[4] Miller, G. A. (2003). Consumerism in Sustainable Tourism: A Survey of UK Consumers. Journal of Sustainable Tourism,11(1), 17-39.

[5] Weisenburg, A., Redington, N. \&Kutyla D. (2008). The staying power of sustainability: Balancing opportunity and risk in the Hospitality Industry.Deloitte Survey Report.

[6] Altinay, L. \&Paraskevas, A. (2008).Planning Research in Hospitality and Tourism. London: Routeledge.

[7] Yin R. K. (2003).Case Study Research: Design and Methods. Thousand Oaks: CA: Sage.

[8] Millar, M. \&Baloglu, S. (2011), Hotel Guests' Preferences for Green Hotel Attributes. Cornell Hospitality Quarterly, 52(3), $302-311$.

[9] Susskind, A. M. (2014). Guest Reactions to In-Room Sustainability Initiatives: An Experimental Look at Product Performance and Guest Satisfaction.Cornell University Quarterly, 55(3), 228-238.

[10] Brotherton, B. \& Wood, R. C. (2008).Researching Tourism and Hospitality: A Student Guide. London: Sage Publications.

[11] Lincoln,Y. S. \&Guba E. G. (1985).Naturalistic Inquiry. London: SAGE.

[12] Miles, M. B. \& Huberman, M. A. (1994).Qualitative Data Analysis. Thousand Oakes:,Sage.

[13] Silverman, D. (2006).Interpreting Qualitative Data. London: Sage Publications.

[14] Ruane, J. M. (2004). Essentials of Research Methods: A Guide to Social Science Research. London: Blackwell.

[15] Neuman, W.(2007).Basics of Social Research: Qualitative and Quantitative Approaches. New York: Pearson.

[16] Shenton, A. K. (2004). Strategies for Ensuring Trustworthiness in qualitative research projects. Education for Information, 22, 63-75.

[17] Patton, M. Q. (2002).Qualitative Evaluation and Research Methods. Newbury Park: CA: Sage.

[18] Wertheimer, A, \& Miller, F. G. (2008). Payment for Research Participation: A Coercive Offer? Journal of Medical Ethics, 34, 389-392.

[19] Jin-Soo, L., Li-Tzang, H., Heesup, H. \&Yunhi, K. (2010). Understanding How Consumers View Green Hotels: How a Hotel's Green Image Can Influence Behavioural Intentions. Journal of Sustainable Tourism,18(7), 901-914.

[20] Barber, N. A. (2014). Profiling the Potential 'Green' Hotel guests: Who are They and What Do They Want? Journal of Hospitality and Tourism Research, 38(3), 361-387.

Citation: Cleopas Njerekai. "A Critique of the Methodological Approaches to Hotel Guest Green Consumerism Empirical Researches Since 2000" International Journal of Research in Tourism and Hospitality (IJRTH), vol 4, no. 1, 2018, pp. 10-17. doi:http://dx.doi.org/10.20431/2455-0043.0401002.

Copyright: () 2018 Authors. This is an open-access article distributed under the terms of the Creative Commons Attribution License, which permits unrestricted use, distribution, and reproduction in any medium, provided the original author and source are credited. 